\title{
Development of the Family Support Scale (FSS) for Newly Pregnant Women
}

\author{
Mohammad Abbas Uddin ${ }^{1 *}$, Minara Khatun ${ }^{2}$ and Yongling Hua ${ }^{3}$ \\ ${ }^{1}$ Research Officer, Directorate General of Nursing and Midwifery, Bangladesh \\ ${ }^{2}$ Teacher, Sylhet Nursing College, Bangladesh \\ ${ }^{3}$ Spinal Surgery Department, First Affiliated Hospital of Dali University, Dali, the People's Republic of China
}

*Corresponding author: Mohammad Abbas Uddin, Research Officer, Directorate General of Nursing and Midwifery, Mohakhali, Dhaka-1212, Bangladesh.
Received Date: May 17, 2021

Published Date: June 24, 2021

\begin{abstract}
Maternal mortality and morbidity are challenging issues particularly for developing countries such as Bangladesh. Pregnant women (particularly newly pregnant women) are vulnerable to both maternal mortality and morbidity. Family support, which varies according to social and family situations, may be an important factor in the welfare of pregnant women. An assessment scale for measuring family support for newly pregnant women would be useful for describing their real living situations. The aim of this study was to develop a vigorous family support scale for newly pregnant women in Bangladesh. The study participants were 30 newly pregnant women (aged between 20 to 30 years) who were asked about the support they perceived that they receive from their families. The developed family support scale was found to be a reliable scale for newly pregnant Bangladeshi women, with an internal consistency reliability level of 0.74 (Cronbach's Alpha Coefficient). The study's findings are considered transferable to other developing countries. The scale can be used to assess newly pregnant women's perceived family support in Bangladesh and other developing countries and can support initiatives to improve family support.
\end{abstract}

Keywords: Newly pregnant women; Family support

\section{Introduction}

Maternal mortality ratio is the annual number of female deaths per 100,000 live births from any cause related to or aggravated by pregnancy or its management (excluding accidental or incidental causes). The mortality ratio includes deaths during pregnancy, childbirth, or within 42 days of termination of pregnancy, irrespective of the duration and site of the pregnancy, for a specified year [1]. Globally, about 99\% of maternal deaths happen in lowand middle-income countries [2]. The Maternal Mortality Ratio in Bangladesh is quite high [3] at 173 deaths/100,000 live births [1], and $13 \%$ of deaths of women aged between 15 and 49 occur due to maternal causes, including hemorrhage and abortion-related complications [4]. In addition, about 14 pregnant mothers die every day while giving birth to children in Bangladesh particularly in the rural areas where inadequate health care including safe delivery care facilities [5]. Maternal health is a national priority in Bangladesh. To reduce maternal deaths, the Bangladesh government has initiated programs such as the prevention of early marriage (before 18 years old) [6], implemented World Health Organization (WHO) recommended ideal antenatal visits [7], increased safe delivery facilities, and encourages the use of skilled maternity services. Additionally, in the district and Upazila levels, government deployed skilled midwives to ensure available and skilled delivery care [8]. In Bangladesh, two ongoing problems are particularly relevant to maternal welfare. Firstly, about one-fourth of the total population 
lives below the poverty level. Secondly, the male-dominated social system creates and perpetuates gender inequality [9]. Also, women are often treated as subordinates by their husbands and are sociallyand economically dependent on them. Under this male domination, many women may not visit a health facility or care provider unless accompanied by a family member, nor can they make spending decisions without the approval of their husband [10]. As a result, many women, particularly pregnant women, are fully- or partially dependent on family support for access to antenatal care.

In rural areas, other factors that may affect pregnant women's health are low economic and nutritional status, ignorance, physical violence, domestic quarrels with husband and in-laws, stress, poor relationships, and absence of family fanning methods [11-14]. Studies found that lack of attention from the husband will lead to increased pregnancy complications [15-16]. Family Support helps families to access services, including formal supports and informal supports to promote the well-being of families with special needs [17]. Thus, a correct tool for measuring this family support system is useful.

Family support is the support that individuals get from other family fellows. This support varies according to the individual and their needs. Pregnancy is a physiological condition where pregnant women need special care and services. Family support is key to meeting pregnant women's needs, ensuring they receive appropriate care and can access necessary services. Good family support also contributes positively to reduced maternal mortality and morbidity and infant mortality and morbidity. The following instruments exist for assessing family support: (a) The Family Support Scale [18]. This 13-item scale is suitable for inpatients and epidemiological studies; (b) The Perceived Social Support from Friends and Family [19] consists of 20 items; the participants were undergraduate students and it was developed in an American cultural context; (c) The Chinese Family Support Scale [20] was developed specifically to measure family support in hypertension patients; (d) The Perceived Family Support Scale to Individuals with Special Needs [21] was developed for hearing-impaired individuals; (e) The Thai Family Support Scale for Elderly Parents [22]; and (f) The Family Support Scale (FSS) for Elderly Persons [23]. Nevertheless, no one of these scales is fit for assessing family support for newly pregnant women in Bangladesh due to traditional, societal, and health care services differences. Consequently, there is an earnest need to develop a family support scale (FSS) for Bangladeshi pregnant women.

\section{Data and Methods}

Family support is the care that pregnant women get from their husband and other household members. It is similarly significant to assess pregnant women's insight that their family is capable and ready to deliver such support. Literature about family support [1823] has been reviewed and the results applied in the development of the current study's Family Support Scale for newly pregnant women.

\section{Sample}

The sample of this research was 30 newly pregnant women who were using a divisional town's model family planning clinic in the Sylhet division of Bangladesh in November 2020. The clinic provides antenatal and other family planning care. Before data collection, the investigator obtained oral permission from the model family planning clinic authority. The researcher assigned a research assistant to data collection. The research assistant was informed of the research's purposes and data collection methods. Newly pregnant women who visited the model family planning clinic for services were considered as participants. After they had accessed the services, they were asked to participate in an interview for data collection. Informed written consent was obtained from those patients who agreed to participate in the interview. The research assistant read the Bengali-language questionnaire to the newly pregnant women and marked their responses on the questionnaire sheet.

\section{Validity of the Family Support Scale for Newly Pregnant Women}

'Content validity' denotes to the precision of a measurement tool. The researcher requested three (03) specialists to evaluate the English version instrument to check its content validity and cultural suitability. The specialists were from the National Institute of Advanced Nursing Education and Research [NIANER], College of Nursing, Sher-E Bangla Nagar, Dhaka and Fozderhat Nursing College, Chittagong, Bangladesh. The final version of the scale was reviewed based on the specialists' remarks. The final English version of the Family Support Scale for newly pregnant women was converted using the back-conversion method [24]. The original English scale was converted into Bengali by an interpreter. The Bengali scale was then converted back to English by another convertor. Subsequently, a third convertor linked the two English forms and recognized any contradictions. These were then corrected.

\section{Instruments}

This study used a self-directed questionnaire, developed by the researcher, originated on current literature about family support. The instrument had two parts. Part 1: the Demographic information with seven items: age, occupation, religion, highest educational level, number of family members, family's monthly income, and husband's occupation. Part 2: the Family Support Scale for newly pregnant women, in which the newly pregnant women evaluated their perception of their family's support for them using 18 criteria: love, family's happiness with, and awareness of, the pregnancy (2 items), health, help, information, emotions, companionship, food, taking of iron and folic acid, sleep, personal needs, health needs, antenatal care, treatment, relationship with family, family's contribution to the participant's happiness, and personal happiness. Each item was assessed via a 4-point, Likertstyle scale, with potential scores ranging from 0 (none) to 3 (much). Total potential scores were between 0 and 54. Greater scores 
indicate greater perceived family support for the newly pregnant women

\section{Results}

\section{Demographic information}

The participants were 30 newly pregnant women between 20 and 30 years old, with a mean age of 21.57 years. Twenty-nine were Muslim and one was Hindu. Twenty-nine were housewives and one was employed. Nine had completed only primary level education, nineteen has also completed secondary level education, one had also completed higher secondary level education, and one had also completed higher level education. Their family sizes were between 2 and 10 people. Family's monthly incomes were between 2000.00 and 25000.00 Taka. Participants' husbands were engaged in private services, business, and other professions (Table 1).

Table 1: Demographic features of the sample $(n=30)$.

\begin{tabular}{|c|c|c|}
\hline Characteristics & Frequency & Percentage \\
\hline $\begin{array}{c}\text { Age } \\
\text { 20-30 years } \\
\text { Mean }=21.57 \text { years }\end{array}$ & 30 & 100.00 \\
\hline \multicolumn{3}{|l|}{ Religion } \\
\hline Islam & 29 & 96.67 \\
\hline Hindu & 01 & 3.33 \\
\hline \multicolumn{3}{|l|}{ Occupation } \\
\hline Housewife & 29 & 96.67 \\
\hline Employee & 01 & 3.33 \\
\hline \multicolumn{3}{|l|}{ Highest education level } \\
\hline Primary & 09 & 30.00 \\
\hline Secondary & 19 & 63.33 \\
\hline Higher secondary & 01 & 3.33 \\
\hline Higher & 01 & 3.33 \\
\hline \multicolumn{3}{|l|}{ Number of family members } \\
\hline $02-05$ & 15 & 50.00 \\
\hline $06-10$ & 15 & 50.00 \\
\hline \multicolumn{3}{|l|}{ Monthly income } \\
\hline 2000.00-12000.00 Taka & 13 & 43.33 \\
\hline 13000.00 Taka and above & 17 & 56.67 \\
\hline \multicolumn{3}{|l|}{ Husband's occupation } \\
\hline Private services & 09 & 30.00 \\
\hline Business & 04 & 13.33 \\
\hline Others & 17 & 56.67 \\
\hline
\end{tabular}

\section{Reliability of the Family Support Scale for Newly Pregnant Women}

The Family Support Scale for newly pregnant women was confirmed for internal consistency reliability. The SPSS program was used to examine the data. All 18 items were entered into the package and analyzed. The result was a Cronbach's Alpha Coefficient of 0.74 (Table $2 \& 3$ ).

This goal of this study was to develop a usable and consistent tool for assessing family support for newly pregnant women. The Family Support tool was developed based on the results of the literature review. Twenty- five areas of support were recognized during the literature review. More than half had contained in earlier studies' tools for assessing family support: love, activities, personal needs [16], information, and company [18], emotional support, health needs, personal needs, treatment, food, and sleep [23]. The present study's researcher also included one common item of "taking good care" which enclosed a variety of support areas, including the family's awareness of the pregnancy, their encouragement with maintaining health, the taking of daily iron and folic acid tablets, antenatal care, and the relationship between the participant and their family. Item analysis was performed. Seven items were deleted to raise the standard level (Cronbach's Alpha Coefficient equal to or more than. .70). The 18 items were selected, and their mean and Standard Deviation given (Table 4). 
Table 2: Reliability of the family support scale (Reliability Statistics).

\begin{tabular}{|c|c|}
\hline Cronbach's Alpha & N of Items \\
\hline .741 & 18 \\
\hline
\end{tabular}

Table 3: Item analysis statistics of family support scale.

\begin{tabular}{|c|l|l|l|}
\hline Item & Mean & Standard deviation & N \\
\hline 1 & 3.0000 & .00000 & 18 \\
\hline 2 & 3.0000 & .00000 & 18 \\
\hline 3 & 2.8000 & .40684 & 18 \\
\hline 4 & 2.7667 & .43018 & 18 \\
\hline 5 & 2.3667 & .49013 & 18 \\
\hline 6 & 2.6333 & .66868 & 18 \\
\hline 7 & 2.8667 & .34575 & 18 \\
\hline 8 & 2.7333 & .44978 & 18 \\
\hline 9 & 2.6000 & .67466 & 18 \\
\hline 10 & 2.7000 & .46609 & 18 \\
\hline 11 & 2.6667 & .47946 & 18 \\
\hline 12 & 2.7667 & .33018 & 18 \\
\hline 13 & 2.9000 & .40513 & 18 \\
\hline 14 & 2.8000 & .52083 & 18 \\
\hline 15 & 2.7333 & .34575 & 18 \\
\hline 16 & 2.8667 & .00000 & 18 \\
\hline 17 & 3.0000 & .00000 & 18 \\
\hline
\end{tabular}

Table 4: Eighteen (18) items of family support for the newly pregnant women.

\begin{tabular}{|c|c|c|c|c|c|}
\hline Item no & Item & No & Little & Some & Much \\
\hline 1 & My family loves me. & 0 & 1 & 2 & 3 \\
\hline 2 & My family is happy with my pregnancy. & 0 & 1 & 2 & 3 \\
\hline 3 & My family is aware of my pregnancy. & 0 & 1 & 2 & 3 \\
\hline 4 & My family encourages me to take care of my health. & 0 & 1 & 2 & 3 \\
\hline 5 & My family helps me in my daily work. & 0 & 1 & 2 & 3 \\
\hline 6 & My family gives me pregnancy-related information. & 0 & 1 & 2 & 3 \\
\hline 7 & My family gives me emotional support. & 0 & 1 & 2 & 3 \\
\hline 8 & My family gives me companionship & 0 & 1 & 2 & 3 \\
\hline 9 & My family is careful about my food. & 0 & 1 & 2 & 3 \\
\hline 10 & My family helps me take daily iron and folic acid tablets & 0 & 1 & 2 & 3 \\
\hline 11 & My family is careful about my sleep. & 0 & 1 & 2 & 3 \\
\hline 12 & My family helps to meet my personal needs. & 0 & 1 & 2 & 3 \\
\hline 13 & My family helps to meet my health needs. & 0 & 1 & 2 & 3 \\
\hline 14 & My family helps me take regular antenatal care. & 0 & 1 & 2 & 3 \\
\hline 15 & My family helps me with treatment & 0 & 1 & 2 & 3 \\
\hline 16 & I have a good relationship with my family. & 0 & 1 & 2 & 3 \\
\hline 17 & My family helps me stay happy. & 0 & 1 & 2 & 3 \\
\hline 18 & I am happy with my family. & 0 & 1 & 2 & 3 \\
\hline
\end{tabular}

Directions: These are queries about your family support. Please tick $(\sqrt{ })$ the one choice that is most suitable for you.

\section{Discussion}

This study aimed to develop a scale to measure the newly pregnant women's perceived family support from the family. The participants were 30 newly pregnant women. They were selected from a family planning clinic located in Sylhet division in Bangladesh. A self-administered scale consisting of 25 questions was used to 
collect the data. The data were analysed and internal consistency reliability (Cronbach's Alpha Coefficient) was found to be less than .70 , below the standard level. To increase the internal consistency reliability level, seven (07) items were gradually deleted. Internal consistency reliability (Cronbach's Alpha Coefficient) was then verified again and was found to be .74 , the standard level. Finally, the 18 items were selected to develop the family support scale (FSS) for newly pregnant women. The limitations of this study were: a) data were collected from a single setting; b) most participants were housewives; c) most participants' highest education levels were primary or secondary.

\section{Conclusion}

The final form of the 18-item FFS is a self-reporting questionnaire which assesses newly pregnant women's perceived family support. An acceptable and standard number of samples were used to collect data. The psychometric properties of the scale were established through back conversion, assessment of cultural suitability, assessment of content validity, and validation of reliability using the SPSS package. The FSS's reliability was above the suitable level [25]

\section{Recommendations}

Further study may be conducted to collect data from different hospital settings, including rural and urban, and from various groups, including the employed and unemployed, the moreeducated and less-educated, and those with small and large families.

\section{Ethical Considerations}

Approval was obtained from the study setting's authority and participants.

\section{Acknowledgments}

The researchers express appreciation to the newly Bangladeshi pregnant females for their co- operation.

\section{Conflicts of Interest}

No conflict of interest has been stated by the researchers.

\section{References}

1. The World Fact Book (2019) Central Intelligence Agency.

2. The World Health Organization (WHO) (2016) Maternal Mortality, Department of Reproductive Health and Research; WHO: Geneva, Switzerland.

3. (2019) New Age, Bangladesh, Maternal mortality rate still high 2019 http://www.newagebd.net/article/73759/maternal-mortality-ratestill-high

4. The Daily Star (2019) Maternal causes behind 13pc deaths.

https://www.thedailystar.net/backpage/bangladesh-maternal-mortalityrate-is-thirteen-percent-survey-says- 1759075

5. Dhaka Tribune (2020) Can skilled midwives reduce maternal and child mortality? https://www.dhakatribune.com/bangladesh/2019/06/30/ can-skilled-midwives-reduce-maternal-and-child-mortality

6. UNICEF (2018) Plan of Action launched to eliminate child marriage in Bangladesh.
7. World Health Organization (2016) WHO recommendations on antenatal care for a positive pregnancy experience: World Health Organization.

8. Directorate general of health services. health bulletin (2018) Dhaka: Ministry of health and family welfare.

9. Sultana AM (2011) Factors effect on women autonomy and decision making power within the household in rural communities. Journal of Applied Sciences Research 7(1): 18-22.

10. Shahabuddin A, Christiana Nöstlinger, Thérèse Delvaux, Malabika Sarker, Alexandre Delamou, et al. (2017) Exploring maternal health care-seeking behavior of married adolescent girls in Bangladesh: a social-ecological approach. PLoS One 12(1): 1-16.

11. Gausia K, Fisher C, Ali M, Oosthuizen J (2009) Magnitude and contributory factors of postnatal depression: a community-based cohort study from a rural subdistrict of Bangladesh. Psychological medicine 39(6): 999-1007.

12. Nasreen HE, Edhborg M, Petzold M, Forsell Y, Kabir ZN (2015) Incidence and risk factor of postpartum depressive symptoms in women: a population based prospective cohort study in a rural district in Bangladesh. J Depress Anxiety 4(1000180): 2167-1044.

13. Islam MJ, Broidy L, Baird K, Mazerolle P (2017) Intimate partner violence around the time of pregnancy and postpartum depression: The experience of women of Bangla-desh. PloS one 12(5): e0176211.

14. Surkan PJ, Sakyi KS, Christian P, Mehra S, Labrique A, Ali H, et al. (2017) Risk of Depressive Symptoms Associated with Morbidity in Postpartum Women in Rural Bangladesh. Maternal and child health journal 21(10): 1890-900.

15. Alio AP, Kornosky JL, Mbah AK, Marty PJ, Salihu HM (2010) The impact of paternal involvement onfeto-infant morbidity among Whites, Blacks and Hispanics. Maternal and child health journal 14(5): 735-741.

16. Misra DP, Caldwell C, Young AA, Abelson S (2010) Do fathers matter? Paternal contributions to birth outcomes and racial disparities. American journal of obstetrics and gynecology 202(2): 99-100.

17. Family Support (2020) School of Social Work University of North Carolina. What is Family Support.

18. Tselebis A, Tania Anagnostopoulou, Dionisios Bratis, Aikaterini Moulou, Alexia Maria, et al. (2011) The 13 item Family Support Scale: Reliability and validity of the Greek translation in a sample of Greek health care professionals. Asia Pacific Family Medi-cine 10: 3.

19. Procidano ME, Heller K (1983) Measures of perceived social support from friends and from family: Three validation studies. American Journal of Community Psychology 11(1): 1-24.

20. Li G, Hu H, Dong Z, Arao T (2013) Development of the Chinese family sup-port scale in a sample of Chinese patients with hypertension. PloS one 8(12): e85682.

21. Mehmet CELIK, YunusEmre AYNA (2014) Application of Perceived Family Support Scale to Individuals with Special Needs. Procedia - Social and Behavioral Sciences 113: 181-190.

22. Komjakraphan, Isalamalai, Boonyasopun, et al. (2009) Development of the Thai family support scale for elderly parents (TFSS-EP). Thai J Nurs Res13(2): 118-132.

23. Uddin MA, Bhuiyan AJ (2019) Development of the family support scale (FSS) for elderly people. MOJ Gerontol Ger 4(1): 17-20.

24. Sperber AD (2004) Translation and validation of study instruments for cross- cultural re-search. Gastroenterology 126: 124-128.

25. Polit DF, Beck CT (2008) Nursing research: Generating and assessing evidence for nursing practice. Lippincott Williams \& Wilkins. 